\title{
Alendronate increased bone mineral density and decreased vertebral fractures in men with osteoporosis
}

\author{
Orwoll E, Ettinger M, Weiss S, et al. Alendronate for the treatment of osteoporosis in men. N Engl J Med 2000 Aug \\ 31;343:604-10.
}

\section{QUESTIONS: In men with osteoporosis, does alendronate prevent or reverse bone loss, and does it decrease vertebral fractures?}

\section{Design}

Randomised \{allocation concealed*\}†, blinded (patients and outcome assessors), $*$ controlled trial with 2 year follow up.

\section{Setting}

20 centres in the US and 10 in other countries.

\section{Patients}

241 men (mean age $63 \mathrm{y}$ ) who met either of the following sets of criteria: bone mineral density (BMD) at the femoral neck $\geqslant 2$ SDs below the mean value in normal young men and a BMD at the lumbar spine $\geqslant 1 \mathrm{SD}$ below the mean value in normal young men; or femoral neck BMD $\geqslant 1$ SD below the mean in normal young men and $\geqslant 1$ vertebral deformity or a history of an osteoporotic fracture. Exclusion criteria included secondary causes of osteoporosis, severe cardiac disease, history of cancer, inability to follow instructions for taking the study drug, and history of treatment for osteoporosis. $86 \%$ of the men in the alendronate group and $83 \%$ in the placebo group completed the study.

\section{Intervention}

Patients were stratified according to free testosterone concentration and allocated in a ratio of 3-2 to receive alendronate, $10 \mathrm{mg} /$ day $(\mathrm{n}=146)$, or placebo $(\mathrm{n}=95)$. All patients received calcium and vitamin D supplements.

\section{Main outcome measures}

Percentage changes in lumbar-spine, femoral-neck, trochanter, hip, and total body BMD and incidence of vertebral fractures.

\section{Main results}

Analysis was by intention to treat. Table 1 shows the absolute differences between the intervention groups on all measures of BMD at 2 years; patients in the alendronate group had greater increases in BMD. The incidence of vertebral fractures was lower in the alendronate group than in the placebo group $(\mathrm{p}=0.02)$ (table 2$)$. Gonadal status did not influence the effect of alendronate on BMD.

\section{Conclusion}

In men with osteoporosis, alendronate increased bone mineral density and decreased the incidence of vertebral fractures.

*See glossary.

†Information provided by author.

Table 1 Percentage changes in bone mineral density from baseline to year 2

\begin{tabular}{llrl} 
Site & Alendronate & Placebo & $\begin{array}{l}\text { Absolute difference } \\
(95 \% \mathrm{Cl})\end{array}$ \\
Lumbar spine & 7.1 & 1.8 & $5.3(4.3$ to 6.3$)$ \\
\hline Femoral neck & 2.5 & -0.1 & $2.6(1.6$ to 3.7$)$ \\
\hline Trochanter & 4.3 & 1.3 & $3.1(1.9$ to 4.4$)$ \\
\hline Hip & 3.1 & 0.6 & $2.6(1.5$ to 3.7$)$ \\
\hline Total body & 2.0 & 0.4 & $1.6(1.0$ to 2.1$)$ \\
\hline
\end{tabular}

Source of funding: Merck.

For correspondence: Dr E Orwoll, Oregon Health Sciences University (CR113), 3181 SW Sam Jackson Park Road, Portland, OR 97201, USA. Fax $+15034944816$

Table 2 Alendronate $v$ placebo at year 2 in men with osteoporosis

\begin{tabular}{lllll} 
Outcome & Alendronate & Placebo & RRR (95\% CI) & NNT (CI) \\
Vertebral fractures & $1 \%$ & $7 \%$ & $89 \%(35$ to 98$)$ & 16 (7 to 56$)$ \\
\hline
\end{tabular}

¥Abbreviations defined in glossary; RRR, NNT, and Cl calculated from data in article.

\section{COMMENTARY}

The risk for a future osteoporotic fracture is independently increased by low BMD and a history of such fractures. ${ }^{1}$ In the study by Orwoll $e t a l$, although $7 \%$ of the placebo group sustained a new vertebral fracture within 2 years, the alendronate group enjoyed almost universal protection from this complication despite a substantial deficit of bone and a $50 \%$ prevalence of vertebral fractures before treatment. This result is impressive and clinically significant. A larger and longer study would probably show that alendronate also prevents fractures at the hip and other non-vertebral sites in men at greatest risk, as it does in women. ${ }^{2}$

Although osteoporotic fractures are less common in men than in women, they are an important cause of death and disability. Whereas almost all women with osteoporosis are postmenopausal, most men with the disease are eugonadal and therefore lose bone for reasons unrelated to testosterone and estradiol. To address the possibility that variable pathogenesis might lead to variable therapeutic outcomes, Orwoll et al stratified patients according to free testosterone levels before assigning treatment. The results conclusively show that gonadal status did not influence the effect of alendronate on BMD. Although this important finding means that the drug is broadly applicable to men with osteoporosis, it also provokes new questions: do bisphosphonate and hormone replacement therapies affect the skeleton equally in hypogonadal men? Would the 2 measures increase BMD more in combination than individually as they do in postmenopausal women?

Clinicians rarely have the opportunity to prescribe a definitively studied remedy that consistently, significantly, and safely alters the course of a common and morbid condition. The work of Orwoll $e t$ al shows that alendronate does precisely that in men with osteoporosis.

1 Ross PD, Davis JW, Epstein RS, et al. Pre-existing fractures and bone mass predict vertebral fracture incidence in women. Ann Intern Med 1991;114:919-23. 2 Black DM, Cummings SR, Karpf DB, et al. Randomised trial of effect of alendronate on risk of fracture in women with existing vertebral fractures. Fracture intervention trial research group. Lancet 1996;348:1535-41.

3 Wimalawansa SJ. A four-year randomised controlled trial of hormone replacement and bisphosphonate, alone or in combination, in women with postmenopausal osteoporosis. Am J Med 1998;104:219-26. 